\title{
Statin Use in the U.S. for Secondary Prevention of Cardiovascular Disease Remains Suboptimal
}

\author{
Quyen Ngo-Metzger, MD, MPH, Samuel Zuvekas, PhD, Paul Shafer, PhD, \\ Howard Tracer, MD, Amanda E. Borsky, DrPH, MPP, and \\ Arlene S. Bierman, MD, MS
}

Background: Atherosclerotic cardiovascular disease (ASCVD) remains the leading cause of mortality in the United States. The purpose of this study is to examine the rates of statin use for secondary prevention of ASCVD events in the United States over the last decade and determine whether disparities in the treatment of ASCVD still persist among women and racial/ethnic minorities.

Methods: We conducted a trend analysis using data from 2008 through 2016 to describe age-adjusted trends in the use of statins for secondary prevention using the Medical Expenditure Panel Survey. We also conducted a multivariable logistic regression analysis to determine whether sociodemographic characteristics are associated with statin use during the 3 years that followed the publication of the 2013 American College of Cardiology/American Heart Association (ACC/AHA) guideline (2014 through 2016).

Results: The prevalence of statin use among those with a history of ASCVD remained unchanged from 2008 through 2016. In 2014 to 2016, more than $40 \%$ of those aged 40 years and older with a history of ASCVD did not use statins, corresponding to approximately 9.5 million Americans. Increasing age and having been diagnosed with high cholesterol (odds ratio $[0 R], 6.22 ; P<.001)$ were associated with higher odds of statin use while being female $(0 R, 0.65 ; P<.001)$ or Hispanic $(0 R, 0.69 ; P=.011)$ were associated with lower odds of statin use.

Conclusions: Our study found there was no increase in the national rates of statin use following the ACC/AHA 2013 secondary prevention guideline and the availability of generic statins. Significant gender and ethnic disparities in ASCVD treatment remained in the United States. (J Am Board Fam Med 2019; 32:807-817.)

Keywords: Atherosclerosis, Cardiovascular Diseases, Chronic Disease, Hypercholesterolemia, Hyperlipidemia, Logistic Models, Preventive Medicine, Secondary Prevention, Statins, Surveys and Questionnaires

Atherosclerotic cardiovascular disease (ASCVD) remains the leading cause of mortality in the United States despite a strong emphasis on preven-

This article was externally peer reviewed.

Submitted 22 October 2018; revised 9 April 2019; accepted 11 April 2019.

From the Agency for Healthcare Research and Quality, Rockville, MD (SZ, PS, HT, AB, ASB); Department of Health Law, Policy, and Management, School of Public Health, Boston University, Boston, MA (PS); Kaiser Permanente School of Medicine (QN-M).

Funding: This paper was supported as part of the Agency for Healthcare Research and Quality intramural research program.

Conflict of interest: none declared.

Corresponding author: Quyen Ngo-Metzger, MD, MPH, Professor, Health Systems Science, Kaiser Permanente School of Medicine, 100 S. Los Robles, Suite 301, Pasadena, CA 91101 (E-mail: Quyen.N.Metzger@kp.org). tion, accounting for more than 800,000 deaths in 2017. ${ }^{1}$ The 2013 American College of Cardiology/ American Heart Association (ACC/AHA) Guideline on the Treatment of Blood Cholesterol to Reduce Atherosclerotic Cardiovascular Risk in Adults recommends statin use for secondary prevention for adults $\leq 75$ years of age with a prior history of ASCVD, specifically recommending that "high-intensity statin therapy should be initiated for those with clinical ASCVD who are not receiving statin therapy" or intensity raised for those already on a lower dose unless contraindicated (eg, history of statin intolerance). ${ }^{2}$ The ACC/AHA guideline also recommends moderate-intensity statin use be considered for secondary prevention in those $>75$ years of age with a history of ASCVD. 
These recommendations were based on numerous studies showing that statins are effective in reducing low-density lipoprotein cholesterol levels, and the risk of death and recurrent coronary and cardiovascular events in those with a history of ASCVD, even in older adults. ${ }^{3-7}$

However, despite this proven effectiveness and the resulting ACC/AHA guideline, several studies have shown persistent underuse of statins in this high-risk population. ${ }^{8-14}$ Of these, we are aware of only a few studies that extend beyond the year that the guideline was published and even then only include narrowly defined populations (eg, only privately insured and/or Medicare patients, those covered by a single insurer, those within 30 days postmyocardial infarction $(\mathrm{MI})) .{ }^{10,11,13,14}$

We examined nationally representative data for the years 2008 through 2016 to determine whether there has been an increase in use of statins in persons with a history of ASCVD following the publication of the ACC/AHA guideline in 2013. Prior studies have tended to focus on narrower samples whereas ours contains a nationally representative sample of adults with any history of ASCVD, the wider population targeted by the ACC/AHA guideline. We also assessed whether individual sociodemographic characteristics are associated with statin use for individuals with a history of ASCVD. Given known disparities in ASCVD treatment among women and racial/ethnic minorities, ${ }^{15-18}$ we wanted to understand whether these disparities persisted using the most current data available. We also capture those who are on Medicaid (only or dually eligible for Medicare) or uninsured, populations that are often missed in claims-based analyses that typically include only those with Medicare and/or private coverage. This study assesses whether rates of statin use for secondary prevention are improving and examines disparities to identify opportunities for improvement.

\section{Methods}

We used the Medical Expenditure Panel Survey (MEPS), a nationally representative survey of the civilian noninstitutionalized population conducted annually by the Agency for Health Care Research and Quality since 1996. ${ }^{19}$ Our analytic sample contains 6084 observations representing 23.4 million people. Our analysis had 2 main components. First, we conducted a trend analysis using data from 2008 through 2016 to describe age-adjusted trends in the use of statins among adults with a history of diagnosed ASCVD. We calculated prevalence of statin use among those with a history of ASCVD in the 40 to 75 years and 76 years and older age groups for each year. We omitted adults aged 21 to 39 years, who are also potentially covered by the ACC/AHA guidelines, because prevalence of ASCVD was low. Then, we conducted a multivariable logistic regression analysis of whether sociodemographic characteristics were associated with statin use among those with a history of ASCVD using pooled data from 2014 through 2016, the 3 years that follow the publication of the 2013 ACC/AHA guidelines. ${ }^{15-18}$

Statin use for secondary prevention was defined as 1 or more prescriptions filled within the calendar year among our population of interest, those aged 40 and older with a history of diagnosed ASCVD. ${ }^{20}$ We identified generic and brand-name statin fills from all prescription drug fills reported using Cerner Multum drug codes and/or medication names. We ascertained history of ASCVD events, to identify the population for which secondary prevention is recommended, from household respondents' answers to the question of whether a doctor or other professional had ever told them they had coronary heart disease, angina, a heart attack, or stroke. Regression models included sociodemographic characteristics (age, sex, race/ethnicity, education, marital status), health status (SF-12 physical component score), health insurance status (Medicare; any private; any Medicaid; uninsured), and geographic area (Census region, living in a Metropolitan Statistical Area). We also examined the association between additional ASCVD risk factors and statin use, including diagnosed hypertension, high cholesterol, and diabetes, as well as smoking status. ${ }^{21}$

We conducted all analyses with Stata/MP 15 (StataCorp, LLC, College Station, TX) using appropriate sample weights and survey estimation techniques to account for the complex sampling design. ${ }^{22}$ Multiple imputation was used to fill in a small number of missing values (at most $2.5 \%$ of sample) for demographic (ie, marital status, education) and health measures (ie, 12-Item Short Form Health Survey (SF-12) Physical Component Summary (PCS), ASCVD risk factors, household respondent-reported diagnosis), matching the approach used in a recently published study using MEPS to estimate the impact of US Preventive 
Figure 1. Statin use among adults with history of diagnosed Ascvd, 2008 to 2016. Source: Agency for Health Care Research and Quality, Medical Expenditure Panel Survey, Full-Year Consolidated Files, 2008 to 2016. Note: All years were age-adjusted to match the 2016 age distribution.

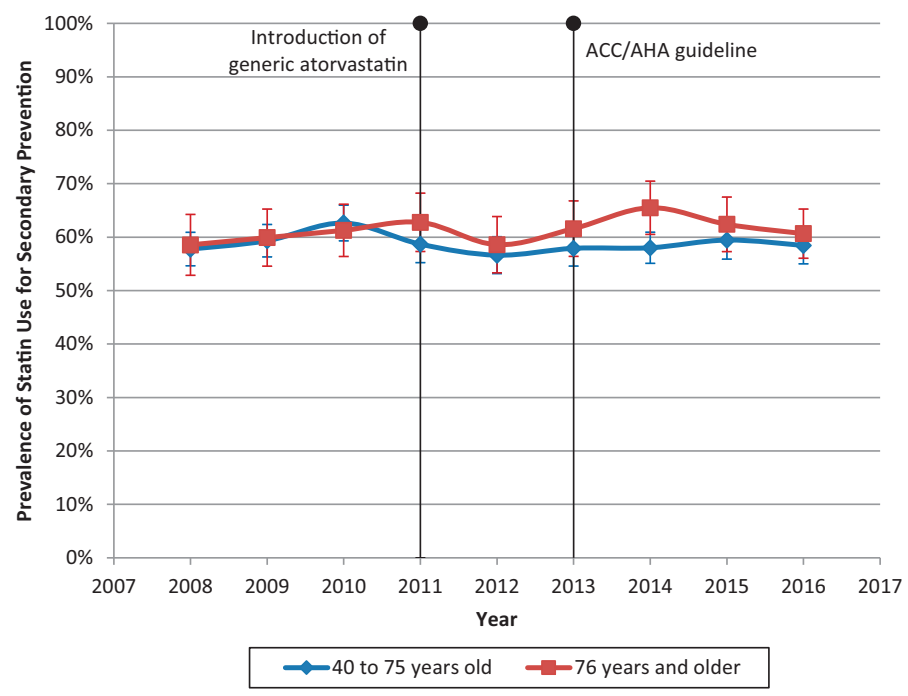

Services Task Force (USPSTF) recommendations on statin use and costs for primary prevention. ${ }^{23}$

\section{Results}

\section{Trends in Statin Use for Secondary Prevention}

Figure 1 shows the age-adjusted US trends for statin use among adults with a history of diagnosed ASCVD aged 40 to 75 years old and aged 76 years and older, respectively, over the 9-year period from 2008 to 2016. The prevalence rate of diagnosed ASCVD did not change significantly over this period (see Appendix). It also shows the years in which the generic statin, atorvastatin, was brought to market in 2011, which may increase utilization through lower costs. Rates of statin use for secondary prevention of ASCVD remained essentially unchanged over this time frame. The observed prevalence of statin use among those with a history of ASCVD went from $57.8 \%$ in 2008 to $58.4 \%$ in 2016 for 40 -to-75-year-olds and from $58.6 \%$ in 2008 to $60.7 \%$ in 2016 for those 76 years and older, but these changes were not statistically significant. We also see no significant changes following the introduction of the ACC/AHA guideline in 2013. In Table 1, we focus on the postguideline period of 2014 to 2016 to describe the population size and characteristics of those using statins for secondary prevention.

\section{Statin Use and Patient Characteristics}

Table 1 shows the sociodemographic characteristics and risk factors for the study population aged
40 years and older with a history of ASCVD. Our MEPS analytic sample included approximately 6000 person-years, representing an estimated average of 23.4 million individuals with ASCVD per year of our study period. An estimated 16.6 million (71\%) were aged 40 to 75 years with the remaining 6.7 million (29\%) aged 76 years and older. A narrow majority of our weighed sample was male (53.7\%). Non-Hispanic whites represented nearly three-quarters of the sample $(73.5 \%)$ followed by non-Hispanic African Americans (11.0\%) and Hispanics $(9.5 \%)$. Nearly all had some form of health insurance (eg, Medicare, Medicaid, or private insurance) with over two-thirds having Medicare $(69.7 \%)$ and another one-fifth having private insurance $(20.4 \%)$. Only $3.9 \%$ reported being uninsured. More than three-quarters (76.2\%) reported history of coronary heart disease, nearly $40 \%$ reported a prior stroke $(39.5 \%)$, and almost a third (31.7\%) reported having diabetes. These are not mutually exclusive, respondents could be represented in one or more categories. Nearly all respondents in this population reported having a nonemergency department usual source of care (92.4\%).

\section{Current Statin Use}

Table 2 shows the proportion of the total population with ASCVD who were taking statins. Among adults aged 40 years and older with ASCVD, nearly 14 million $(59.4 \%)$ were using statins on average from 2014 through 2016 after the ACC/AHA rec- 
Table 1. Demographic and Health Characteristics of Adults Aged 40 Years and Older with History of Diagnosed ASCVD, 2014 to 2016

\begin{tabular}{|c|c|c|c|}
\hline Characteristic & $\mathrm{n}$ & Weighted \% & $95 \% \mathrm{CI}$ \\
\hline \multicolumn{4}{|l|}{ Age.in years } \\
\hline 40 to 49 & 595 & 8.7 & (7.6 to 9.8$)$ \\
\hline 50 to 59 & 1,247 & 17.3 & (15.9 to 18.7$)$ \\
\hline 60 to 64 & 804 & 12.6 & (11.4 to 13.7$)$ \\
\hline 65 to 69 & 871 & 15.2 & (13.7 to 16.7$)$ \\
\hline 70 to 75 & 946 & 17.4 & (15.8 to 19.0$)$ \\
\hline 76 to 79 & 513 & 9.2 & (8.1 to 10.2$)$ \\
\hline 80 to 84 & 562 & 9.9 & (8.9 to 10.9$)$ \\
\hline 85 and above & 546 & 9.8 & (8.6 to 11.0$)$ \\
\hline \multicolumn{4}{|l|}{ Sex } \\
\hline Women & 3,039 & 46.3 & (44.5 to 48.1$)$ \\
\hline Men & 3,045 & 53.7 & (51.9 to 55.5$)$ \\
\hline \multicolumn{4}{|l|}{ Race/ethnicity } \\
\hline Hispanic & 1,124 & 9.5 & (8.0 to 11.0$)$ \\
\hline Non-Hispanic, white & 3,198 & 73.5 & (71.3 to 75.7$)$ \\
\hline $\begin{array}{l}\text { Non-Hispanic, African } \\
\text { American }\end{array}$ & 1,320 & 11.1 & (9.7 to 12.6$)$ \\
\hline Non-Hispanic, Asian & 254 & 2.7 & (2.0 to 3.5$)$ \\
\hline Non-Hispanic, Other & 188 & 3.1 & (2.2 to 4.0$)$ \\
\hline \multicolumn{4}{|l|}{ Marital status } \\
\hline Unmarried & 3,159 & 44.5 & (42.3 to 46.7 ) \\
\hline Married & 2,925 & 55.5 & (53.3 to 57.7$)$ \\
\hline \multicolumn{4}{|l|}{ Education } \\
\hline $\begin{array}{l}\text { Did not complete high } \\
\text { school }\end{array}$ & 2,322 & 31.1 & (29.3 to 32.8 ) \\
\hline $\begin{array}{l}\text { High school graduate } \\
\text { or GED }\end{array}$ & 1,304 & 22.4 & (20.7 to 24.1 ) \\
\hline Some college & 1,407 & 24.9 & (23.1 to 26.7 ) \\
\hline $\begin{array}{l}\text { College degree or } \\
\text { higher }\end{array}$ & 991 & 21.0 & (19.2 to 22.9$)$ \\
\hline \multicolumn{4}{|l|}{ Insurance coverage } \\
\hline Medicare & 4,064 & 69.7 & (67.8 to 71.6$)$ \\
\hline Private & 1,124 & 20.4 & (18.7 to 22.1 ) \\
\hline Medicaid & 568 & 6.0 & (5.1 to 6.9$)$ \\
\hline Uninsured & 328 & 3.9 & (3.2 to 4.6$)$ \\
\hline \multicolumn{4}{|l|}{ Census region } \\
\hline Northeast & 1,003 & 17.8 & (15.8 to 19.8$)$ \\
\hline Midwest & 1,231 & 22.5 & (20.2 to 24.9 ) \\
\hline South & 2,628 & 40.8 & (38.1 to 43.5$)$ \\
\hline West & 1,222 & 18.8 & (17.0 to 20.7 ) \\
\hline \multicolumn{4}{|l|}{ MSA } \\
\hline MSA & 5,024 & 81.3 & (78.1 to 84.6 ) \\
\hline Non-MSA & 1,060 & 18.7 & (15.4 to 21.9$)$ \\
\hline \multicolumn{4}{|l|}{$\begin{array}{l}\text { History of cardiovascular } \\
\text { disease }\end{array}$} \\
\hline $\begin{array}{l}\text { CHD to MI to or } \\
\text { angina }\end{array}$ & 4,555 & 76.2 & (74.6 to 77.9$)$ \\
\hline Stroke & 2,538 & 39.5 & (37.8 to 41.2 ) \\
\hline
\end{tabular}

Continued
Table 1. Continued

\begin{tabular}{lccc}
\hline Characteristic & $\mathrm{n}$ & Weighted \% & $95 \%$ CI \\
\hline $\begin{array}{l}\text { ASCVD risk factors } \\
\quad \text { Doctor ever told high } \\
\quad \text { cholesterol }\end{array}$ & 4,504 & 75.1 & (73.4 to 76.8$)$ \\
$\quad \begin{array}{l}\text { Doctor ever told had } \\
\text { hypertension }\end{array}$ & 4,982 & 80.9 & (79.4 to 82.4) \\
$\quad \begin{array}{l}\text { Doctor ever told had } \\
\quad \text { diabetes }\end{array}$ & 2,122 & 31.7 & $(29.8$ to 35.6$)$ \\
$\quad \begin{array}{l}\text { Current smoker } \\
\text { Usual source of care }\end{array}$ & 1,020 & 16.8 & $(15.1$ to 18.4$)$ \\
$\quad$ No & 531 & 7.9 & $(6.8$ to 8.9$)$ \\
$\quad$ Yes & 5,553 & 92.1 & $(91.1$ to 93.2$)$ \\
\hline
\end{tabular}

Source: Agency for Healthcare Research and Quality, Medical Expenditure Panel Survey 2014 to 2016.

ASCVD, atherosclerotic cardiovascular disease; CHD, coronary heart disease; CI, confidence interval; ED, emergency department; GED, General Equivalency Diploma; MI, myocardial infarction; MSA, Metropolitan Statistical Area.

ommendation for statin use for secondary prevention was published. Among the 16.6 million persons with ASCVD who are aged 40 to 75 years, 9.7 million $(58.3 \%)$ were using statins while among the 6.7 million persons with ASCVD aged 76 years or older, 4.2 million $(62.3 \%)$ were using statins, indicating that older adults in this at risk population are using statins at a higher rate.

Table 3 shows the adjusted odds of statin use associated with various sociodemographic and health status characteristics. Statin use for secondary prevention was more likely with increasing age, plateauing in the 65-to-84-years age range before beginning to drop off. All persons age 50 years and higher had significantly higher odds of statin use relative to those aged 40 to 49 years with a history of ASCVD. The age groups with the highest odds of statin use were among 76-to-79-year-olds (odds ratio [OR], 3.43; 95\% CI, 2.14 to 5.49$)$ and 65 -to69-year-olds (OR, 3.36; 95\% CI, 2.15 to 5.22). Female sex (OR, $0.65 ; 95 \%$ CI, 0.55 to 0.77 ) was associated with decreased odds of using statins for secondary prevention. Hispanic ethnicity was associated significantly lower odds of reporting statin use (OR, $0.69 ; 95 \%$ CI, 0.52 to 0.92$)$, nearly a third lower than that of non-Hispanic whites. Married persons were more likely to be taking statins for secondary prevention (OR, 1.26; 95\% CI, 1.02 to 1.57). All education levels (high school diploma or GED, some college, college degree or higher) had higher estimated odds of statin use than those who did not complete high school; however, only the 
Table 2. Statin Use in Adults with History of Diagnosed ASCVD by Age Group, 2014 to 2016

\begin{tabular}{lccccc}
\hline & \multicolumn{2}{c}{ Total Population } & & \multicolumn{2}{c}{ Statin Users } \\
\cline { 2 - 3 } & $\mathrm{N}$ & $\begin{array}{c}\text { Weighted Population, } \\
\text { Millions (95\% CI) }\end{array}$ & & $\begin{array}{c}\text { Weighted Users, } \\
\text { Millions (95\% CI) }\end{array}$ & Weighted \% (95\% CI) \\
\hline Age 40 years and older & 6,084 & $23.4(22.1$ to 24.6$)$ & & $13.9(13.0$ to 14.8$)$ & $59.4(57.4$ to 61.5) \\
Age 40 to 75 years & 4,463 & $16.6(15.7$ to 17.6$)$ & & $9.7(9.0$ to 10.4$)$ & $58.3(55.9$ to 60.6$)$ \\
Age 76 years and older & 1,621 & $6.7(6.2$ to 7.3$)$ & & $4.2(3.8$ to 4.7$)$ & $62.3(59.0$ to 65.7) \\
\hline
\end{tabular}

ASCVD, atherosclerotic cardiovascular disease; CI, confidence interval.

Source: Agency for Healthcare Research and Quality, Medical Expenditure Panel Survey, 2014 to 2016.

result for some college was statistically significant (OR, 1.39; 95\% CI, 1.08 to 1.80). Among risk factors for ASCVD, those who reported ever being told by a doctor that they had high cholesterol had the highest odds of being on a statin (OR, 6.22; $95 \%$ CI, 5.02 to 7.72 ). Those who were ever told they had diabetes (OR, 1.51; 95\% CI, 1.24 to 1.85 ) or hypertension (OR, 1.33; 95\% CI, 1.08 to 1.65 ) also had significantly higher odds of being on a statin; however, current smoking was not associated with increased odds of statin use after controlling for other risk factors and socioeconomic characteristics. A 1-point increase in SF-12 Physical Component Score (a scale from 0 to 100), indicating better health, was associated with slightly higher odds of statin use (OR, 1.01; 95\% CI, 1.00 to 1.02). Having a usual source of care, regardless of setting, was associated with a near doubling of odds of statin use for secondary prevention $(\mathrm{OR}, 1.87 ; 95 \%$ CI, 1.37 to 2.56). An alternate model (not shown) that split usual sources of care by setting found no significant differences in odds of statin use between those with a nonemergency department usual source of care (hospital OR, 1.92; nonhospital OR, 1.79; yes but setting unknown OR, 1.74) so we did not include that in the model presented. There were no significant differences in the odds of statin use by health insurance status, Census region, or living in an Metropolitan statistical area (MSA).

\section{Discussion}

Our study is the first to show national trends in statin use following the AHA/ACC 2013 guideline. We find nearly flat trends in statin use for secondary prevention, despite the introduction of a generic statin over the last decade (eg, generic atorvastatin in 2011). Unfortunately, gaps in recommended ASCVD services are not unique to statins for secondary prevention or other recom- mended clinical services. ${ }^{24,25}$ For example, less than $35 \%$ of patients who reported having an acute myocardial infarction received cardiac rehabilitation. ${ }^{26,27}$

We find a gender disparity in statin use for secondary prevention, consistent with prior research, ${ }^{28,29}$ finding that women have approximately $35 \%$ lower odds of statin use after accounting for other demographic and health factors. Though the prevalence of ASCVD is higher in men, ASCVD mortality is actually higher among women and there is no evidence that statins are less effective for secondary prevention or not tolerated as well by women as men. ${ }^{29-32}$ People of Hispanic ethnicity had approximately $30 \%$ lower odds of receiving statins for secondary prevention. ${ }^{33-36} \mathrm{We}$ also found that adults who had a usual source of care, were married, and had higher education had greater odds of statin use, which is consistent with prior research. ${ }^{37-40}$

Understanding barriers to statin use-including patient, clinician, and delivery system factors as well as costs-is important when identifying strategies to improve quality of care. Statins are now available to many Americans at little-to-no out-ofpocket cost regardless of whether they are being used for primary or secondary prevention. ${ }^{41,42}$ Many insurers had already lowered or eliminated cost sharing for statins for those with a history of ASCVD. The Patient Protection and Affordable Care Act of 2010 (ACA) required that private insurers provide first-dollar coverage for services and medications with an "A" or " $\mathrm{B}$ " grade from the USPSTF without cost-sharing for primary prevention. ${ }^{43-45}$ Some insurers responded by reducing the out-of-pocket costs for certain generic statins to zero regardless of indication. ${ }^{46}$ Lower out-ofpocket costs have been associated with increased prescription fills for and adherence to statin ther- 
Table 3. Odds of Current Statin Use and Sociodemographic Characteristics, Adults Aged 40 Years and Older with History of Diagnosed ASCVD, 2014 to $2016(n=6,039)$

\begin{tabular}{|c|c|c|c|}
\hline Characteristic & Odds Ratio & $(95 \% \mathrm{CI})$ & $P$-Value \\
\hline \multicolumn{4}{|l|}{ Age, in years } \\
\hline 40 to 49 (reference) & 1.00 & - & - \\
\hline 50 to 59 & 1.60 & $(1.14$ to 2.26$)$ & .007 \\
\hline 60 to 64 & 2.43 & $(1.66$ to 3.56$)$ & $<.001$ \\
\hline 65 to 69 & 3.36 & $(2.15$ to 5.22$)$ & $<.001$ \\
\hline 70 to 75 & 3.09 & $(2.02$ to 4.74$)$ & $<.001$ \\
\hline 76 to 79 & 3.43 & $(2.14$ to 5.49$)$ & $<.001$ \\
\hline 80 to 84 & 3.03 & $(1.93$ to 4.74$)$ & $<.001$ \\
\hline 85 and above & 2.03 & $(1.27$ to 3.24$)$ & .003 \\
\hline Female & 0.65 & $(0.55$ to 0.77$)$ & $<.001$ \\
\hline \multicolumn{4}{|l|}{ Race/ethnicity } \\
\hline Non-Hispanic, white (reference) & 1.00 & - & - \\
\hline Hispanic & 0.69 & $(0.52$ to 0.92$)$ & .011 \\
\hline Non-Hispanic, African American & 0.81 & (0.63 to 1.04$)$ & .102 \\
\hline Non-Hispanic, Asian & 1.25 & (0.82 to 1.90$)$ & .297 \\
\hline Non-Hispanic, other & 0.70 & $(0.40$ to 1.21$)$ & .201 \\
\hline Has a usual source of care & 1.87 & $(1.37$ to 2.56$)$ & $<.001$ \\
\hline Doctor ever told high cholesterol & 6.22 & $(5.02$ to 7.72$)$ & $<.001$ \\
\hline Doctor ever told had high blood pressure & 1.33 & $(1.08$ to 1.65$)$ & .009 \\
\hline Doctor ever told had diabetes & 1.51 & $(1.24$ to 1.85$)$ & $<.001$ \\
\hline Current smoker & 0.90 & (0.70 to 1.14$)$ & .375 \\
\hline SF-12 Physical Component Score & 1.01 & $(1.00$ to 1.02$)$ & .022 \\
\hline Married & 1.26 & $(1.02$ to 1.57$)$ & .033 \\
\hline \multicolumn{4}{|l|}{ Education } \\
\hline Did not complete high school (reference) & 1.00 & - & - \\
\hline High school graduate or GED & 1.23 & $(1.00$ to 1.52$)$ & .055 \\
\hline Some college & 1.39 & $(1.08$ to 1.80$)$ & .011 \\
\hline College degree or higher & 1.15 & $(0.87$ to 1.51$)$ & .339 \\
\hline \multicolumn{4}{|l|}{ Insurance coverage } \\
\hline Private (reference) & 1.00 & - & - \\
\hline Medicare & 1.05 & $(0.76$ to 1.44$)$ & .781 \\
\hline Medicaid & 1.13 & $(0.78$ to 1.63$)$ & .527 \\
\hline Uninsured & 0.90 & $(0.60$ to 1.35$)$ & .607 \\
\hline \multicolumn{4}{|l|}{ Census region } \\
\hline Northeast (reference) & 1.00 & - & - \\
\hline Midwest & 1.17 & $(0.88$ to 1.55$)$ & .271 \\
\hline South & 0.82 & (0.62 to 1.08$)$ & .165 \\
\hline West & 0.90 & (0.67 to 1.22$)$ & .504 \\
\hline MSA & 1.11 & (0.85 to 1.44$)$ & .451 \\
\hline Constant & 0.04 & (0.02 to 0.08$)$ & $<.001$ \\
\hline
\end{tabular}

ASCVD, atherosclerotic cardiovascular disease; CI, confidence interval; GED, General Equivalency Diploma; MSA, metropolitan statistical area; SF-12, 12-Item Short Form Health Survey (SF-12).

Source: Agency for Healthcare Research and Quality, Medical Expenditure Panel Survey, 2014 to 2016.

apy, ${ }^{43,47}$ which have been subsequently associated with a reduction in rates of major cardiovascular events among those with a prior myocardial infarction. ${ }^{44}$ Despite removal of several potential system level barriers to statin use-the availability of generic statins, and potentially lower costs—we found no significant change in overall rates of statin use for secondary prevention.

Prior research has documented that primary care physicians perceive side effects to be one of the most common reasons for statin discontinuation. ${ }^{48}$ Patients also perceive side effects to be a significant 
barrier, as well as potential risks to health, and concern about prolonged dependence on medications. ${ }^{49}$ Any interaction with a provider provides an opportunity for physicians and patients to discuss both side effects, which are associated with discontinuation of statin therapy, ${ }^{48}$ and patient preferences, ${ }^{50-53}$ which contribute to shared decision making between providers and patients. Despite this, there has been little assessment of how practice characteristics (eg, size, specialty, payer mix) interact with uptake of guideline-recommended statin use as of yet. ${ }^{48,50-53,48}$ The association of provider and/or practice characteristics associated with diffusion of clinical guidelines is an area ripe for future research to increase delivery of guideline-concordant care.

\section{Limitations}

Our analysis has several limitations. First, MEPS is nationally representative of the civilian noninstitutionalized population and therefore excludes active-duty military personnel, people residing in nursing homes or other long-term health care facilities, and people incarcerated in jail or prison. Second, in MEPS, ASCVD history and risk factors are based on self reports of current smoking status and reports of whether a doctor has ever told them that they have various health conditions. Though underreporting of visits is common in MEPS, self reports of health status have been found to be generally consistent with clinical measures. ${ }^{54,55}$ Our estimates of the proportion of the population with ASCVD, also based on household reporting are quantitatively similar to estimates derived from National Health and Nutrition Examination Survey using clinical measurements. ${ }^{35,56}$ Third, in MEPS, statin use and prescription fills are based on household-reported data combined with records provided by household-reported pharmacies, which may be subject to error. ${ }^{20}$ This could lead to our estimates being an understatement of the prevalence of statin use for secondary prevention; however, total prescription fills for lipid-lowering agents reported in MEPS do correspond reasonably well with industry estimates, and these data have been used in other studies of statin use. ${ }^{9,12,20,57-60,61}$ Fourth, some people may experience statin-associated side effects. While national datasets do not capture the clinical reasons for why someone may stop a medication to distinguish true intolerance from other side effects, the 2018 ACC/
AHA guidelines note that most patients are able to tolerate statins by changing to an alternative statin, or changing the regimen or dose. ${ }^{62}$ Fifth, while peripheral arterial disease was not included in our study's definition of ASCVD, prior research has found that more than half of patients with peripheral arterial disease also have cardiovascular disease (CVD), ${ }^{63}$ and thus, would have been included in our study population. Lastly, we were not able to distinguish whether people were receiving high, moderate, or low intensity statins, which is another important component of examining appropriate statin use.

\section{Conclusions}

Significant differences in statin use by age and gender and ethnic disparities in statin use for secondary prevention persist, despite no clinical basis for lower effectiveness among women and Hispanics. For populations that are at high risk of a recurrent ASCVD event, this gap of nearly $40 \%$ of those with a history of ASCVD not taking statins is an area where improvement is critically needed. Health information technology and electronic health records may potentially be leveraged for practice improvement. ${ }^{64} \mathrm{Be}-$ havioral change will require health systems, providers, and patients to all play a role in increasing cardiovascular health and lowering the large burden of ASCVD on morbidity and mortality.

The findings and conclusions in this document are those of the author(s), who are responsible for its content, and do not necessarily represent the views of AHRQ. No statement in this report should be construed as an official position of AHRQ or of the US Department of Health and Human Services.

To see this article online, please go to: http://jabfm.org/content/ 32/6/807.full.

\section{References}

1. Benjamin EJ, Virani SS, Callaway CW, et al. Heart Disease and Stroke Statistics_-2018 Update: a report from the American Heart Association. Circulation 2018;137:e67-e492.

2. Stone NJ, Robinson JG, Lichtenstein AH, et al. 2013 ACC/AHA guideline on the treatment of blood cholesterol to reduce atherosclerotic cardiovascular risk in adults: a report of the American College of Cardiology/American Heart Association Task Force on Practice Guidelines. Circulation 2014;129(25 Suppl 2):S1e-S45.

3. Koskinas KC, Siontis GCM, Piccolo R, et al. Effect of statins and non-statin LDL-lowering medications on cardiovascular outcomes in secondary prevention: 
a meta-analysis of randomized trials. Eur Heart J 2018;39:1172-1180.

4. Long-Term Intervention with Pravastatin in Ischaemic Disease (LIPID) Study Group. Prevention of cardiovascular events and death with pravastatin in patients with coronary heart disease and a broad range of initial cholesterol levels. $\mathrm{N}$ Engl J Med 1998;339:1349-1357.

5. Scandinavian Simvastatin Survival Study Group. Randomised trial of cholesterol lowering in 4444 patients with coronary heart disease: the Scandinavian Simvastatin Survival Study (4S). Lancet 1994; 344:1383-1389.

6. Rodriguez F, Maron DJ, Knowles JW, Virani SS, Lin S, Heidenreich PA. Association between intensity of statin therapy and mortality in patients with atherosclerotic cardiovascular disease. JAMA Cardiol 2017;2:47-54.

7. Navarese EP, Robinson JG, Kowalewski M, et al. Association between baseline LDL-C level and total and cardiovascular mortality after LDL-C lowering: a systematic review and meta-analysis. JAMA 2018; 319:1566-1579.

8. Booth JN 3rd, Colantonio LD, Rosenson RS, et al. Healthcare utilization and statin re-initiation among medicare beneficiaries with a history of myocardial infarction. J Am Heart Assoc 2018;7(10).

9. Johansen ME, Green LA, Sen A, Kircher S, Richardson CR. Cardiovascular risk and statin use in the United States. Ann Fam Med 2014;12:215-223.

10. Peters SAE, Colantonio LD, Zhao H, et al. Sex differences in high-intensity statin use following myocardial infarction in the United States. J Am Coll Cardiol 2018;71:1729-1737.

11. Rosenson RS, Farkouh ME, Mefford M, et al. Trends in use of high-intensity statin therapy after myocardial infarction, 2011 to 2014. J Am Coll Cardiol 2017;69:2696-2706.

12. Salami JA, Warraich H, Valero-Elizondo J, et al. National trends in statin use and expenditures in the US adult population from 2002 to 2013: insights from the Medical Expenditure Panel Survey. JAMA Cardiol 2017;2:56-65.

13. Olufade T, Zhou S, Anzalone D, et al. Initiation patterns of statins in the 2 years after release of the 2013 American College of Cardiology/American Heart Association (ACC/AHA) Cholesterol Management Guideline in a large US health plan. J Am Heart Assoc 2017;6(5).

14. Okerson T, Patel J, DiMario S, Burton T, Seare J, Harrison DJ. Effect of 2013 ACC/AHA Blood Cholesterol Guidelines on statin treatment patterns and low-density lipoprotein cholesterol in atherosclerotic cardiovascular disease patients. J Am Heart Assoc 2017;6(3).

15. Pool LR, Ning H, Lloyd-Jones DM, Allen NB. Trends in racial/ethnic disparities in cardiovascular health among US adults from 1999-2012. J Am Heart Assoc 2017;6(9).

16. Lu Y, Ezzati M, Rimm EB, Hajifathalian K, Ueda P, Danaei G. Sick Populations and sick subpopulations: reducing disparities in cardiovascular disease between Blacks and whites in the United States. Circulation 2016;134:472-485.

17. Kuzawa CW, Sweet E. Epigenetics and the embodiment of race: developmental origins of US racial disparities in cardiovascular health. Am J Hum Biol 2009;21:2-15.

18. Lewey J, Shrank WH, Bowry AD, Kilabuk E, Brennan TA, Choudhry NK. Gender and racial disparities in adherence to statin therapy: a meta-analysis. Am Heart J 2013;165:665-678, 678.e661.

19. Agency for Healthcare Research and Quality. Survey background. 2009. Available from: https://meps. ahrq.gov/mepsweb/about_meps/survey_back.jsp. Accessed June 7, 2018.

20. Hill SC, Zuvekas SH, Zodet MW. Implications of the accuracy of MEPS prescription drug data for health services research. Inquiry 2011;48:242-259.

21. Machlin S, Cohen J, Elixhauser A, Beauregard K, Steiner C. Sensitivity of household reported medical conditions in the medical expenditure panel survey. Med Care 2009;47:618-825.

22. Stata Statistical Software: Release 14 [Computer Program]. College Station, TX. StataCorp LP; 2015.

23. Ngo-Metzger Q, Zuvekas SH, Bierman AS. Estimated impact of US Preventive Services Task Force recommendations on use and cost of statins for cardiovascular disease prevention. J Gen Intern Med 2018;33:1317-1323.

24. Borsky A, Zhan C, Miller T, Ngo-Metzger Q, Bierman AS, Meyers D. Few Americans receive all highpriority, appropriate clinical preventive services. Health Aff (Millwood) 2018;37:925-928.

25. McGlynn EA, Asch SM, Adams J, et al. The quality of health care delivered to adults in the United States. N Engl J Med 2003;348:2635-2645.

26. Fang J, Ayala C, Luncheon C, Ritchey M, Loustalot F. Use of outpatient cardiac rehabilitation among heart attack survivors-20 states and the District of Columbia, 2013 and four states, 2015. MMWR Morb Mortal Wkly Rep 2017;66:869-873.

27. Thomas RJ, Balady G, Banka G, et al. 2018 ACC/ AHA Clinical Performance and Quality Measures for Cardiac Rehabilitation: A Report of the American College of Cardiology/American Heart Association Task Force on Performance Measures. J Am Coll Cardiol 2018;71:1814-1837.

28. Mosca L, Linfante AH, Benjamin EJ, et al. National study of physician awareness and adherence to cardiovascular disease prevention guidelines. Circulation 2005;111:499-510. 
29. Keyhani S, Scobie JV, Hebert PL, McLaughlin MA. Gender disparities in blood pressure control and cardiovascular care in a national sample of ambulatory care visits. Hypertension 2008;51:1149-1155.

30. Mosca L, Barrett-Connor E, Wenger NK. Sex/gender differences in cardiovascular disease prevention: what a difference a decade makes. Circulation 2011; 124:2145-2154.

31. Baigent C, Keech A, Kearney PM, et al. Efficacy and safety of cholesterol-lowering treatment: prospective meta-analysis of data from 90,056 participants in 14 randomised trials of statins. Lancet 2005;366:12671278.

32. Enriquez JR, Pratap P, Zbilut JP, Calvin JE, Volgman AS. Women tolerate drug therapy for coronary artery disease as well as men do, but are treated less frequently with aspirin, beta-blockers, or statins. Gender Med 2008;5:53-61.

33. Gu A, Kamat S, Argulian E. Trends and disparities in statin use and low-density lipoprotein cholesterol levels among US patients with diabetes, 1999-2014. Diabetes Res Clin Pract 2018;139:1-10.

34. Gamboa CM, Colantonio LD, Brown TM, Carson AP, Safford MM. Race-Sex Differences in Statin Use and Low-Density Lipoprotein Cholesterol Control Among People With Diabetes Mellitus in the Reasons for Geographic and Racial Differences in Stroke Study. J Am Heart Assoc 2017;6(5).

35. Adedinsewo D, Taka N, Agasthi P, Sachdeva R, Rust G, Onwuanyi A. Prevalence and factors associated with statin use among a nationally representative sample of US adults: National Health and Nutrition Examination Survey, 2011-2012. Clin Cardiol 2016; 39:491-496.

36. Qureshi WT, Kaplan RC, Swett K, et al. American College of Cardiology/American Heart Association (ACC/AHA) Class I Guidelines for the treatment of cholesterol to reduce atherosclerotic cardiovascular risk: implications for US Hispanics/Latinos based on findings from the Hispanic Community Health Study/Study of Latinos (HCHS/SOL). J Am Heart Assoc 2017;6(5).

37. Kripalani S, Goggins K, Nwosu S, et al. Medication nonadherence before hospitalization for acute cardiac events. J Health Commun 2015;20(Suppl 2):34-42.

38. Havranek EP, Mujahid MS, Barr DA, et al. Social determinants of risk and outcomes for cardiovascular disease: a scientific statement from the American Heart Association. Circulation 2015;132:873-898.

39. Ndumele CD, Baer HJ, Shaykevich S, Lipsitz SR, Hicks LS. Cardiovascular disease and risk in primary care settings in the United States. Am J Cardiol 2012;109:521-526.

40. Spatz ES, Sheth SD, Gosch KL, et al. Usual source of care and outcomes following acute myocardial infarction. J Gen Intern Med 2014;29:862-869.
41. The Patient Protection and Affordable Care Act. In. Vol 42 U.S.C. $\$ 180012010$.

42. U.S. Department of Health and Human Services, Centers for Medicare \& Medicaid Services, The Center for Consumer Information \& Insurance Oversight,. Affordable Care Act Implementation FAQs-Set 18. n.d. Available from: https://www. cms.gov/CCIIO/Resources/Fact-Sheets-and-FAQs/ aca_implementation_faqs $18 . h t m l$.

43. Watanabe JH, Kazerooni R, Bounthavong M. Association of copayment with likelihood and level of adherence in new users of statins: a retrospective cohort study. J Manag Care Pharm 2014;20:43-50.

44. Choudhry NK, Avorn J, Glynn RJ, et al. Full coverage for preventive medications after myocardial infarction. N Engl J Med 2011;365:2088-2097.

45. Bibbins-Domingo K, Grossman DC, Curry SJ, et al. Statin Use for the Primary Prevention of Cardiovascular Disease in Adults: US Preventive Services Task Force Recommendation Statement. JAMA 2016; 316:1997-2007.

46. Brandeis University. Zero copayment for certain statin prescriptions. n.d. Available from: https:// www.brandeis.edu/humanresources/benefits/pdfs/ 2018/OptumRx_Statin_Prescriptions.pdf. Accessed August 6, 2018.

47. Karaca-Mandic P, Swenson T, Abraham JM, Kane RL. Association of Medicare Part D medication outof-pocket costs with utilization of statin medications. Health Serv Res 2013;48:1311-1333.

48. Tanner RM, Safford MM, Monda KL, et al. Primary care physician perspectives on barriers to statin treatment. Cardiovasc Drugs Ther 2017;31:303309.

49. Ju A, Hanson CS, Banks E, et al. Patient beliefs and attitudes to taking statins: systematic review of qualitative studies. Br J Gen Pract 2018;68:e408-e419.

50. Booth JN 3rd, Colantonio LD, Chen L, et al. Statin discontinuation, reinitiation, and persistence patterns among medicare beneficiaries after myocardial infarction: a cohort study. Circ Cardiovasc Qual Outcomes 2017;10(10).

51. Izuka NJ, Alexander MAW, Balasooriya-Smeekens C, Mant J, De Simoni A. How do stroke survivors and their carers use practitioners' advice on secondary prevention medications? Qualitative study of an online forum. Fam Pract 2017;34:612-620.

52. Ofori-Asenso R, Jakhu A, Zomer E, et al. Adherence and persistence among statin users aged 65 years and over: a systematic review and meta-analysis. J Gerontol A Biol Sci Med Sci 2018;73:813-819.

53. Inselman J, Branda $M$, Castaneda-Guarderas A, et al. Uptake and documentation of the use of an encounter decision aid in usual practice: a retrospective analysis of the use of the statin/aspirin choice decision aid. Med Decis Making 2016;36:557-561. 
54. Zuvekas SH, Olin GL. Validating household reports of health care use in the medical expenditure panel survey. Health Serv Res 2009;44(5 Pt 1):1679-1700.

55. Cheak-Zamora NC, Wyrwich KW, McBride TD. Reliability and validity of the SF-12v2 in the medical expenditure panel survey. Qual Life Res 2009;18: 727-735.

56. Mercado C, DeSimone AK, Odom E, Gillespie C, Ayala C, Loustalot F. Prevalence of cholesterol treatment eligibility and medication use among adults-United States, 2005-2012. MMWR Morb Mortal Wkly Rep 2015;64:1305-1311.

57. Johansen ME, Hefner JL, Foraker RE. Antiplatelet and statin use in US patients with coronary artery disease categorized by race/ethnicity and gender, 2003 to 2012. Am J Cardiol 2015;115:1507-1512.

58. Sarpong EM, Zuvekas SH. Trends in statin therapy among adults (age $\geq 18$ ), United States, 2000 to 2011. In: Statistical Brief (Medical Expenditure Panel Survey (US)). Rockville, MD: Agency for Healthcare Research and Quality (US); 2001.

59. Sarpong EM, Zuvekas SH. Changes in statin therapy among adults (age $\geq 18$ ) by selected characteristics, United States, 2000-2001 to 2010-2011. In: Statistical Brief (Medical Expenditure Panel Survey (US)).
Rockville, MD: Agency for Healthcare Research and Quality (US); 2001.

60. IMS Institute for Health Informatics. Medicines Use and Spending in the U.S., A Review of 2015 and Outlook to 2020. 2016. Available from: https:// morningconsult.com/wp-content/uploads/2016/04/ IMS-Institute-US-Drug-Spending-2015.pdf.

61. Toth PP, Patti AM, Giglio RV, et al. Management of statin intolerance in 2018: still more questions than answers. Am J Cardiovasc Drugs 2018;18:157173.

62. Grundy SM, Stone NJ, Bailey AL, et al. AHA/ACC/ AACVPR/AAPA/ABC/ACPM/ADA/AGS/APhA/ ASPC/NLA/PCNA Guideline on the Management of Blood Cholesterol. J Am Coll Cardiol 2018;2018: 25709.

63. Hirsch AT, Criqui MH, Treat-Jacobson D, et al. Peripheral arterial disease detection, awareness, and treatment in primary care. JAMA 2001;286:13171324.

64. Cohen JD, Aspry KE, Brown AS, et al. Use of health information technology (HIT) to improve statin adherence and low-density lipoprotein cholesterol goal attainment in high-risk patients: proceedings from a workshop. J Clin Lipidol 2013;7:573-609. 


\section{Appendix}

Table 4. Prevalence Rate of Diagnosed ASCVD, 2008 to 2016

\begin{tabular}{lcc}
\hline Year & Prevalence Per 1000 & $95 \%$ CI \\
\hline 2008 & 161.0 & 151.3 to 170.6 \\
2009 & 157.5 & 148.8 to 166.3 \\
2010 & 153.7 & 145.5 to 162.0 \\
2011 & 149.5 & 140.7 to 158.3 \\
2012 & 147.6 & 138.7 to 156.6 \\
2013 & 155.3 & 146.9 to 163.7 \\
2014 & 156.6 & 147.9 to 165.3 \\
2015 & 153.4 & 144.6 to 162.2 \\
2016 & 152.6 & 144.6 to 160.6 \\
\hline
\end{tabular}

ASCVD, atherosclerotic cardiovascular disease. Adjusted Wald test to Prob $>\mathrm{F}=0.1931$. 